\title{
Review
}

\section{Oleuropein Aglycone: A Possible Drug against Degenerative Conditions. In Vivo Evidence of its Effectiveness against Alzheimer's Disease}

\author{
Fiorella Casamenti ${ }^{\mathrm{a}, *}$, Cristina Grossi $^{\mathrm{a}}$, Stefania Rigacci ${ }^{\mathrm{b}}$, Daniela Pantano $^{\mathrm{a}}$, Ilaria Luccarini ${ }^{\mathrm{a}}$ \\ and Massimo Stefani ${ }^{\mathrm{b}}$ \\ ${ }^{\mathrm{a}}$ Department of Neuroscience, Psychology, Drug Research and Child Health, Division of Pharmacology and \\ Toxicology, University of Florence, Florence, Italy \\ ${ }^{\mathrm{b}}$ Department of Experimental and Clinical Biomedical Sciences "Mario Serio", University of Florence, Florence, \\ Italy
}

Accepted 19 December 2014

\begin{abstract}
The amyloid plaques and neurofibrillary tangles found in the Alzheimer's disease (AD) brain arise as a result of selfassembly into fibrillar material of amyloid- $\beta$ protein $(A \beta)$ and hyperphosphorylated tau, respectively, through a pathological process starting with the appearance of aggregation nuclei and neurotoxic oligomers. Accordingly, the search of inhibitors of oligomer nucleation and growth is considered a promising target to prevent amyloid toxicity. In recent years, a number of dietary factors including antioxidants, vitamins, and polyphenols have been characterized for their ability to protect cells stressed by several factors including the presence of amyloid deposits as well as to inhibit amyloid self-assembly and cytotoxicity and some of them are currently in clinical trial. The present review summarizes the findings on the beneficial effects against neurodegeneration and other peripheral inflammatory and degenerative diseases of oleuropein aglycone (OLE), a natural phenol abundant in the extra virgin olive oil. The data presently available suggest that OLE could provide a protective and therapeutic effect against a number of pathologies, including $\mathrm{AD}$ as well as obesity, type 2 diabetes, non-alcoholic hepatitis, and other natural or experimentally-induced pathological conditions. Such a protection could result, at least in part, in a remarkable improvement of the pathological signs arising from stress conditions including oxidative stress, an excessive inflammatory response, and the presence of cytotoxic aggregated material. In particular, the recent data on the cellular and molecular correlates of OLE neuroprotection suggest it could also play a therapeutic role against $\mathrm{AD}$.
\end{abstract}

Keywords: Alzheimer's disease, amyloid- $\beta$ deposits, autophagy, epigenetics, polyphenols, TgCRND8 mice

\footnotetext{
${ }^{*}$ Correspondence to: Fiorella Casamenti, Department of Neuroscience, Psychology, Drug Research and Child Health, Division of Pharmacology and Toxicology, University of Florence, 50139 Florence, Italy. Tel.: +39055 4271242; Fax: +39 055 4271280; E-mail: fiorella.casamenti@unifi.it.
}

\section{INTRODUCTION}

Focusing dietary regimens associated with a reduced risk of degenerative diseases in the aged population can be useful to find molecules exploitable for their prevention and therapy. Mounting evidence supports the beneficial effects of the Mediterranean and Asian diets in delaying aging and in preventing age-related 
dysfunctions, cancer, diabetes, and neurodegenerative diseases [1-5]. In particular, Mediterranean diet appears effective against AD-like pathology and cognitive deterioration, attenuating mild cognitive impairment and its conversion to AD. The beneficial effects of the Mediterranean and Asian diets in reducing age-related dysfunctions could be the consequence of the presence, in specific foods characterizing those alimentary regimens, of substantial amounts of specific polyphenols whose beneficial properties include the ability to interfere with amyloid aggregation [7-10]. Oleuropein and its aglycone (OLE) are the major polyphenols in the leaves and drupes of Oleaceae, particularly Olea Europaea, yet with different abundancies in the various cultivars, and in the extra virgin olive oil (EVOO) thereof [11]. Studies in rodents suggest that diet supplementation with phenol-rich components of the Mediterranean diet such as red wine and EVOO improves several pathological conditions, with particular emphasis on aging- and disease-associated cognitive and behavioral deficits [12]. Similar data have been reported for other polyphenols, such as curcumin and epigallocatechin3-gallate found in turmeric and green tea, respectively, abundantly consumed in the Asian diet [13, 14].

It was previously found that OLE interferes with amylin [15], tau [16], and $A \beta$ peptide aggregation and toxicity both in vitro [7] and in an $A \beta$ expressing C. elegans transgenic strain [17]. Subsequently, the implementation of that research carried out with the TgCRND8 mouse model of $A \beta$ deposition showed that OLE administration results in a significant reduction of soluble and aggregated $\mathrm{A} \beta$ in $\mathrm{AD}$-relevant brain areas with a significant attenuation of $A \beta$-mediated cognitive deterioration $[5,18]$. This mini-review summarizes the main results that have led to suggest the usefulness of OLE to combat, among other, age-associated neurodegeneration and dementia.

\section{OLE COUNTERACTS THE SIGNS OF A NUMBER OF DEGENERATIVE CONDITIONS RESULTING FROM OXIDATIVE STRESS AND INFLAMMATION}

Previous studies carried out in vivo such as those performed with mice models of spinal cord injury [19], carrageenan-induced pleurisy [20], collagen-induced arthritis [21], and intestinal ischemia-reperfusion injury [22] have shown that OLE possesses remarkable anti-inflammatory activity [23]. Other studies have indicated that OLE possesses other biochemical and pharmacological activities, including cardioprotective, antioxidant, antiatherogenic, anticancer, antimicrobial, and antiviral effects (reviewed in [24]). Finally, it has been reported that OLE and other polyphenols found in olive oil are able to prevent low density lipoprotein oxidation and platelet aggregation and to inhibit lipoxygenase and eicosanoid production [25]. For all these reasons in recent years OLE has become an important subject of study. In particular, the effects of OLE and other natural polyphenols on living systems recall those produced by a healthy level of caloric restriction, which is recommended to improve aging reducing the risk of age-associated diseases, including dementia. These similarities have led to propose that the beneficial effects of the Mediterranean/Asian diets result from their rich content of polyphenols [26].

\section{OLE PROTECTS AGAINST TYPE 2 DIABETES AND OTHER CONDITIONS THAT CHARACTERIZE THE METABOLIC SYNDROME}

Besides the protective effects against a number of pathologies with uncontrolled oxidative stress and inflammatory reaction outlined above, recent research has shown the effectiveness of OLE against obesity [27], type 2 diabetes [28] and the hepatic steatosis induced by a high-fat diet in mice [29]. Taken together, these data support a beneficial action of OLE against some of the signs of the metabolic syndrome, a complex pathological condition affecting an increasing number of people in advanced countries. In particular, OLE supplementation to high-fat diet mice reversed the increase of liver weight together with that of hepatic and plasma lipid levels; this occurred possibly through downregulation of the expression of Wnt10b-inhibitor genes and the Toll-like receptormediated signaling molecules (TLR2, TLR4) and pro-inflammatory cytokines. The expression of several transcription factors and their target genes involved in adipogenesis, was also downregulated, whereas the expression of $\beta$-catenin was upregulated [29]. These results have led these authors to suggest that OLE protects against high fat-induced hepatic steatosis in mice through Wnt10b- and fibroblast growth factor receptor-1 (FGFr1)-mediated signaling involved in liver lipogenesis together with TLR2 and TLR4 signaling involved in hepatic steatosis.

A recent randomized, double-blind, placebocontrolled crossover trial was carried out in New 
Zealand with 46 middle-aged participants, with medium-high body-mass index and at risk of developing the metabolic syndrome, receiving an oral dose of OLE ( $50 \mathrm{mg}+10 \mathrm{mg}$ hydroxythyrosol) or of placebo for 12 weeks. At the end of the treatment, the results showed that, as compared to placebo, people fed with OLE displayed a $15 \%$ improvement in insulin sensitivity and a $28 \%$ improvement of pancreatic $\beta$-cell responsiveness and secretory capacity, with increased concentrations of interleukin 6 (IL-6) and insulin-like growth factor-binding protein $1 / 2$ (IGFBP-1/2), without any evident negative effect on hepatic and other physiological parameters [28]. Taken together, these data agree with those previously reported on OLE interference with the normal path of amylin aggregation in vitro with lack of appearance of cytotoxic oligomers [15].

\section{PLANT POLYPHENOLS ARE EFFECTIVE AGAINST ALZHEIMER'S DISEASE}

$\mathrm{AD}$ is the most common form of dementia presently affecting, in developed countries, approximately 30 million aged people, and those numbers are expected to triple by 2050 . The key histopathological sign of $\mathrm{AD}$ is the presence, in several brain areas, of hyperphosphorylated tau aggregates and tangles, of minute extracellular amyloid $(\mathrm{A} \beta)$ deposits found in diffuse and senile plaques and around cerebral vessels and dystrophic/degenerating neurites. Plaque deposits, mainly composed of polymeric fibrils of the 42 amino acid peptide $\left(A \beta_{42}\right)$ generated by membrane amyloid- $\beta$ protein precursor proteolysis $[30,31]$, are thought to be responsible for the functional alterations and behavioral deficits that characterize AD [30]. Recently, the interest in deciphering the relationship between plaque burden and neuronal death has focused on the importance, as the main neurotoxic species, of the oligomeric pre-fibrillar assemblies originating at the onset of fibril growth [32]. The latter evidence contributed to explain the lack of relation between plaque load and AD severity [33]; it also shifted the search of treatments able to delay $\mathrm{AD}$ occurrence and to relieve its symptoms from the development of molecules able to hinder fibril growth to that of molecules effective in counteracting the appearance of toxic oligomeric intermediates [34]. Several therapeutic approaches inhibiting amyloidogenic protein self-assembly into oligomers and fibrils are under development; in particular, increasing interest is devoted to the anti-amyloidogenic activity of plant polyphenols present in several foods such as resveratrol, OLE, curcumin, and epigallocatechin-3gallate [8]. In particular, recent work has provided the most complete set of data concerning the beneficial effects of OLE [5, 7, 17, 18]. These include the behavioral, biological, biophysical, biochemical, and electrophysiological correlates of OLE protection against neurodegeneration which characterizes AD.

\section{OLE REDUCES COGNITIVE IMPAIRMENT AND IMPROVES SYNAPTIC FUNCTION IN TgCRND8 MICE}

The beneficial effects of dietary supplementation of OLE were investigated in the TgCRND8 (Tg) mice, a widely used model of $A \beta$ deposition $[5,18]$. These $\mathrm{Tg}$ mice are cognitively impaired by the age of 3 months [35] and develop a pattern of $A \beta$ deposition recalling several aspects of human $\operatorname{AD}[36,37]$. By the same age, mice display small sized $A \beta_{42}$-immunopositive plaques in various brain areas, including the cortex and the hippocampus. Upon aging, plaque number increases, reaching the maximum roughly by 7-9 months of age; moreover, the plaques become larger, from small-medium to big in size and radiating in shape and acquire a compact core [36]. In addition, in later life stages, from 6 to 12 months of age, this $\mathrm{Tg}$ strain exhibits, throughout the cortical and hippocampal areas, plaques with a huge amount of pyroglutamylated 3-42A $\beta$ (pE3-A $\beta$ ) largely exceeding that of $A \beta_{42}$ [18]. This $A \beta_{42}$ derivative is produced by the activity of glutaminyl cyclase (QC) and is increasingly considered a key player in $\mathrm{A} \beta$ aggregation and plaque growth [38]. Two types of $\mathrm{pE}-\mathrm{A} \beta$ plaques are found in the human hippocampus, focal and diffuse, the former associated with QC-expressing interneurons [39] thus supporting the close $\mathrm{pE}-\mathrm{A} \beta / \mathrm{QC}$ relation and its association with cognitive decline in $\mathrm{AD}$ [40]. Moreover, the finding that $\mathrm{QC}$ expression and $\mathrm{pE}-\mathrm{A} \beta$ burden increase with Braak stages [41] further stresses the importance of these factors in $\mathrm{AD}$ pathogenesis.

Wild type (wt) and $\mathrm{Tg}$ mice of three age groups (1.5, 4.0 and 10.0 months) were treated for 8 weeks with a modified low-fat $(5.0 \%)$ AIN-76A diet either as such (untreated mice) or supplemented with $50 \mathrm{mg}$ OLE $/ \mathrm{kg}$ of diet (OLE-fed mice) [5], following DL 116/92, Directive 86/609/EEC and National guidelines for animal care (P.N. 283/2012-B). At the end of treatment, the wt and $\mathrm{Tg}$ mice were checked for cognitive performance. Untreated 3-6-month old Tg mice were unable to memorize the punishment and to perform the inhibitory avoidance in the step-down 
passive avoidance test; they were also unable to discriminate between the familiar and the novel object in the object recognition test [5]. However, OLE-fed mice displayed a remarkable improvement in both behavioral tests, with scores reaching those displayed by age-matched wt controls. The improved results in cognitive tests were associated with a significant amelioration of synaptic function, as assessed by long-term potentiation experiments in CA1 hippocampal slices of aged Tg mice incubated with OLE or with vehicle $1.0 \mathrm{~h}$ before and during all electrophysiological recordings [18]. Interestingly, similar results were obtained with slices exposed to suberoylanilide hydroxamic acid (SAHA), an histone deacetylase-2 inhibitor, suggesting some epigenetic involvement (see below).

\section{OLE REDUCES SOLUBLE A $\beta$, PLAQUE LOAD/DENSITY, AND GLIA REACTION IN TgCRND8 MICE}

The improvement of OLE-fed $\mathrm{Tg}$ mice in cognitive tests was accompanied by a significant reduction of $\mathrm{A} \beta_{40} / \mathrm{A} \beta_{42}$ and $\mathrm{pE} 3-\mathrm{A} \beta$ levels and $\mathrm{A} \beta$ plaque size and compactness in the brain tissue, in agreement with the in vitro anti-aggregation effect of OLE $[7,18]$. In the older Tg mice, OLE administration not only prevented amyloid deposition but also favored disaggregation of preformed plaques [5], that appeared "fluffy" and less cored in the neuron surroundings (Fig. 1). In the hippocampus and cortices of 12-month-old OLE-fed Tg mice, Thioflavin $S$ staining, which marks $A \beta$ fibrils, revealed a significant reduction in the number and total
$\mathrm{A} \beta$ plaque area (Fig. 2A, B); moreover, most plaques displayed reduced size and a ribbon-like/diffuse core, as compared to those imaged in untreated $\mathrm{Tg}$ mice. As we already reported employing $\mathrm{OC}$ and $\mathrm{pE} 3-\mathrm{A} \beta$ antibodies [18], in both OLE-fed and untreated 12month-old Tg mice an overlap of the staining of the $\mathrm{pE} 3-\mathrm{A} \beta$ (blue) and Thioflavin S (green) was detected in the entire plaque where $\mathrm{pE} 3-\mathrm{A} \beta$ blue staining was particularly intense in the plaque core (Fig. 2A). This effect was also the consequence of a significant reduction of QC expression in the brain of OLE-fed mice, whereas the polyphenol had no effect on QC activity in vitro [18]. The molecular mechanism of this finding has not been determined; however, it appears to be of critical importance to drive the beneficial effects of OLE associated with plaque load reduction.

As already reported for young/middle-aged Tg mice [5], $A \beta_{40}$ and $A \beta_{42}$ sodium dodecyl sulphate and formic acid soluble fractions measured in the cortex of 12-month-old OLE-fed Tg mice were significantly reduced as compared to untreated $\mathrm{Tg}$ mice (Fig. 2C). Furthermore, in the aged OLE-fed $\mathrm{Tg}$ mice, the decreased $A \beta$ load was paralleled by a less intense $A \beta$ associated glia reaction, in terms of reduced astrocyte activation, as shown by the presence of fewer and less reactive astrocytes throughout the brain and reduced glial fibrillary acidic protein levels (Fig. 3).

\section{OLE TRIGGERS AUTOPHAGY}

In $\mathrm{AD}$, plaque load results from complex equilibria between $A \beta$ deposition and clearance, where
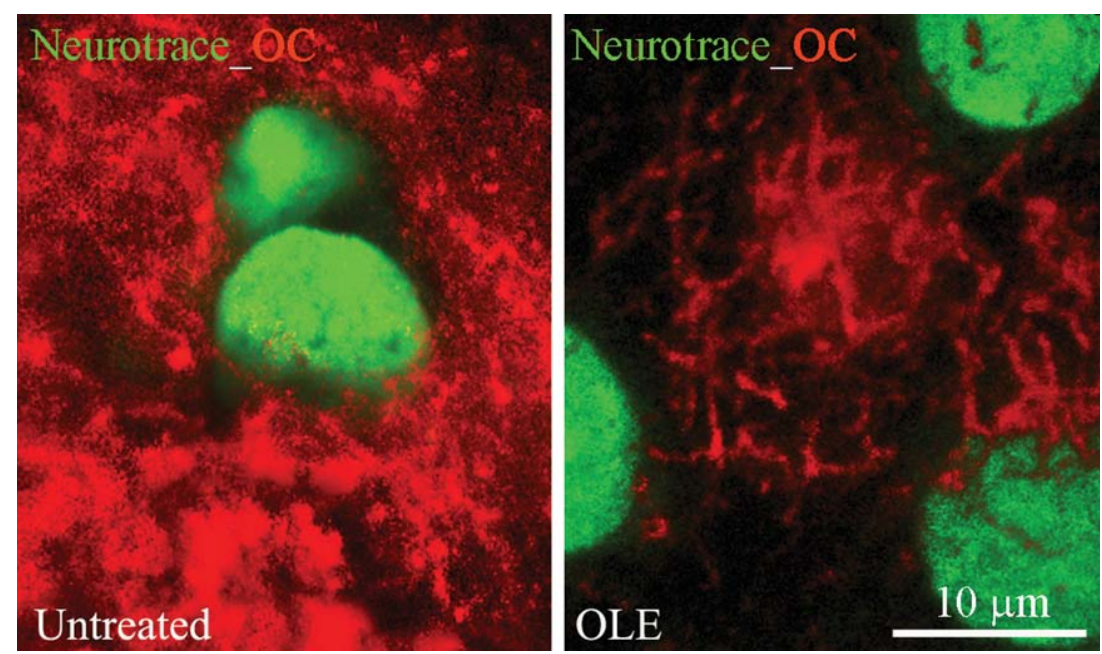

Fig. 1. Representative photomicrographs showing neurons (green) within compact and fluffy amyloid plaques, stained by OC antibody (red), in untreated and OLE administered TgCRND8 mice. 
A
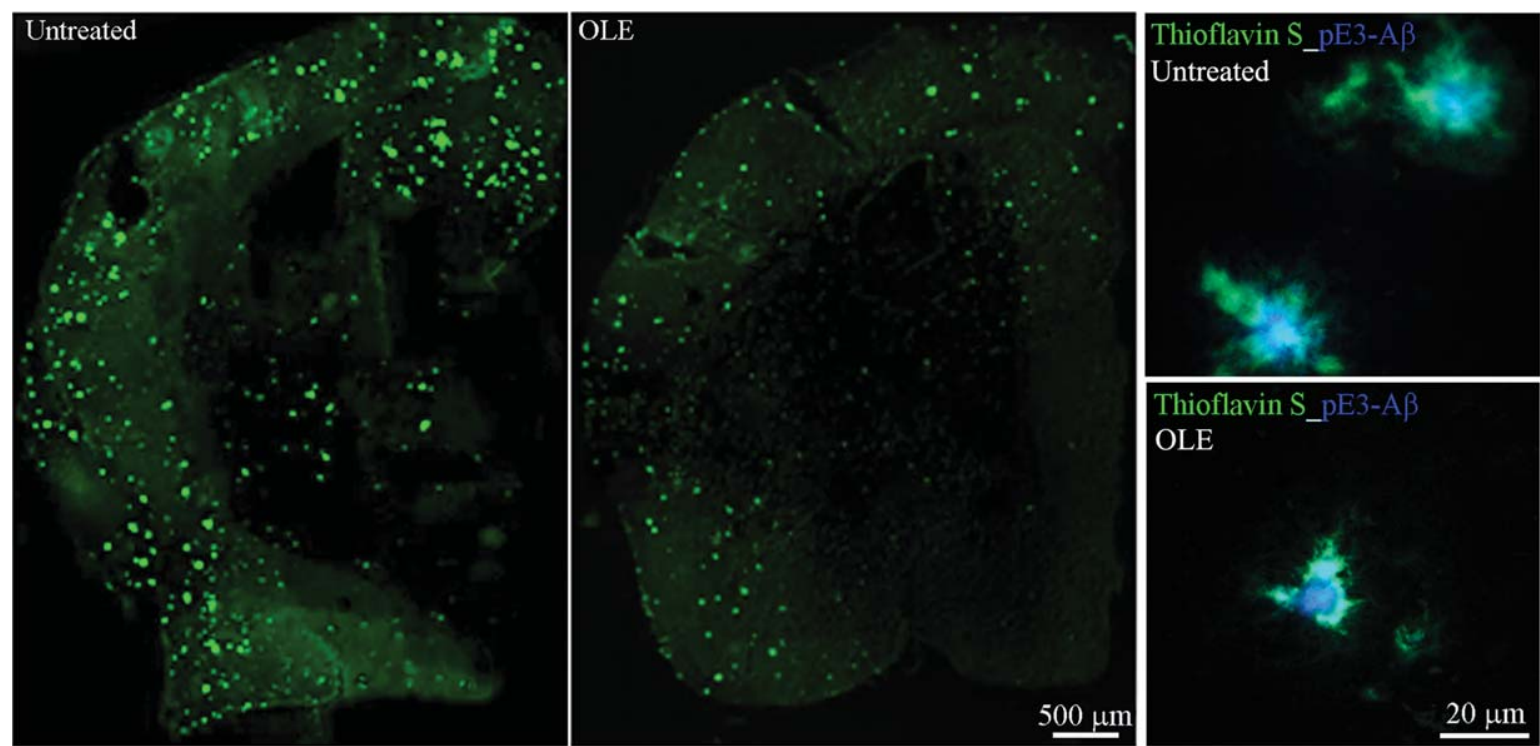

B
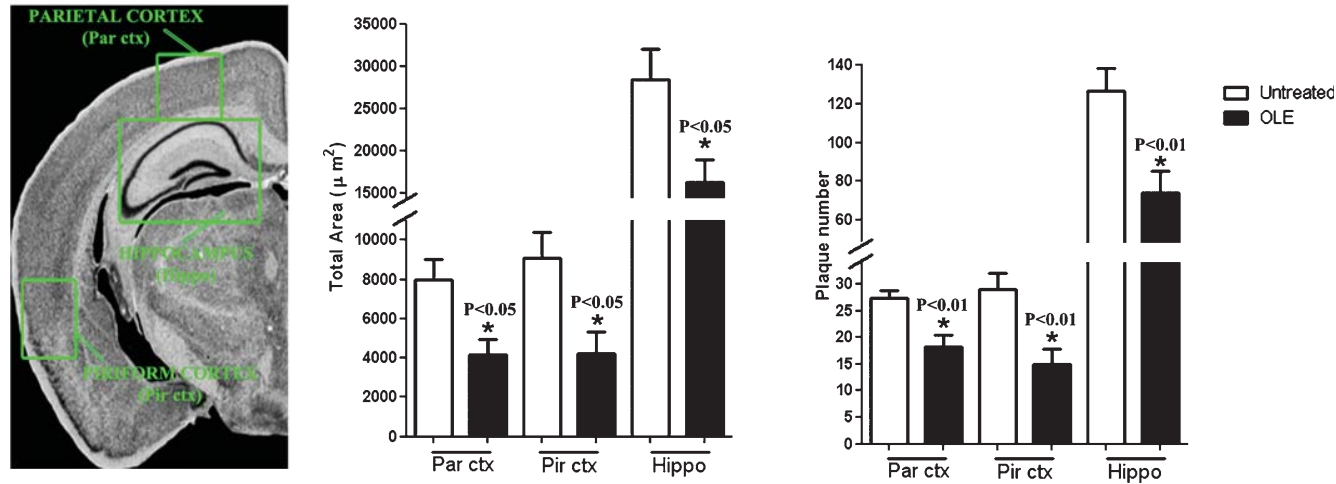

C

A $\beta 40$ ELISA

SDS

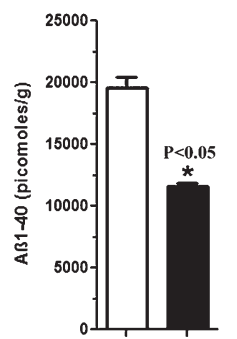

FA

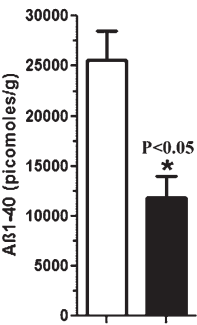

SDS

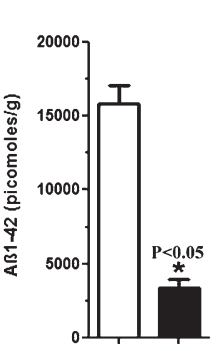

A $\beta 42$ ELISA

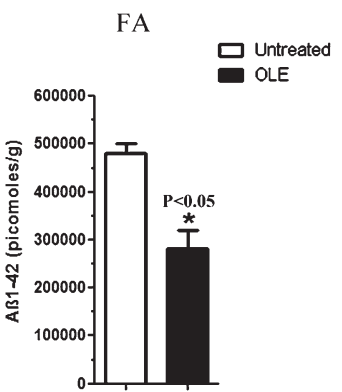

Fig. 2. Thioflavin S staining in untreated and OLE-fed TgCRND8 mice. A) OLE administration reduces Thioflavin S positive plaque burden (green) in the hemibrain of 12-month-old TgCRND8 mice; $\mathrm{pE} 3-\mathrm{A} \beta$ (blue) and Thioflavin $\mathrm{S}$ (green) staining co-localizes in cored $\mathrm{A} \beta$ deposits of both Tg groups. B) Quantitative analysis of Thioflavin S stained plaque area and plaque number in 12-month-old untreated and OLE-fed Tg mice ( $n=5$ /group, six sections/mouse) in the parietal and piriform cortices and in the hippocampus (squared areas indicate in the left hemibrain image). C) ELISA: cortical levels of sodium dodecyl sulphate- and formic acid-soluble $A \beta_{40}$ and $A \beta_{42}$ peptides. Both $A \beta_{40}$ and $A \beta_{42}$ levels were significantly decreased in OLE-fed Tg versus age-matched untreated Tg mice ( $n=5 /$ group). Data are reported as mean values \pm S.E.M. Statistical analysis: two-tailed unpaired Student's $t$-test. 

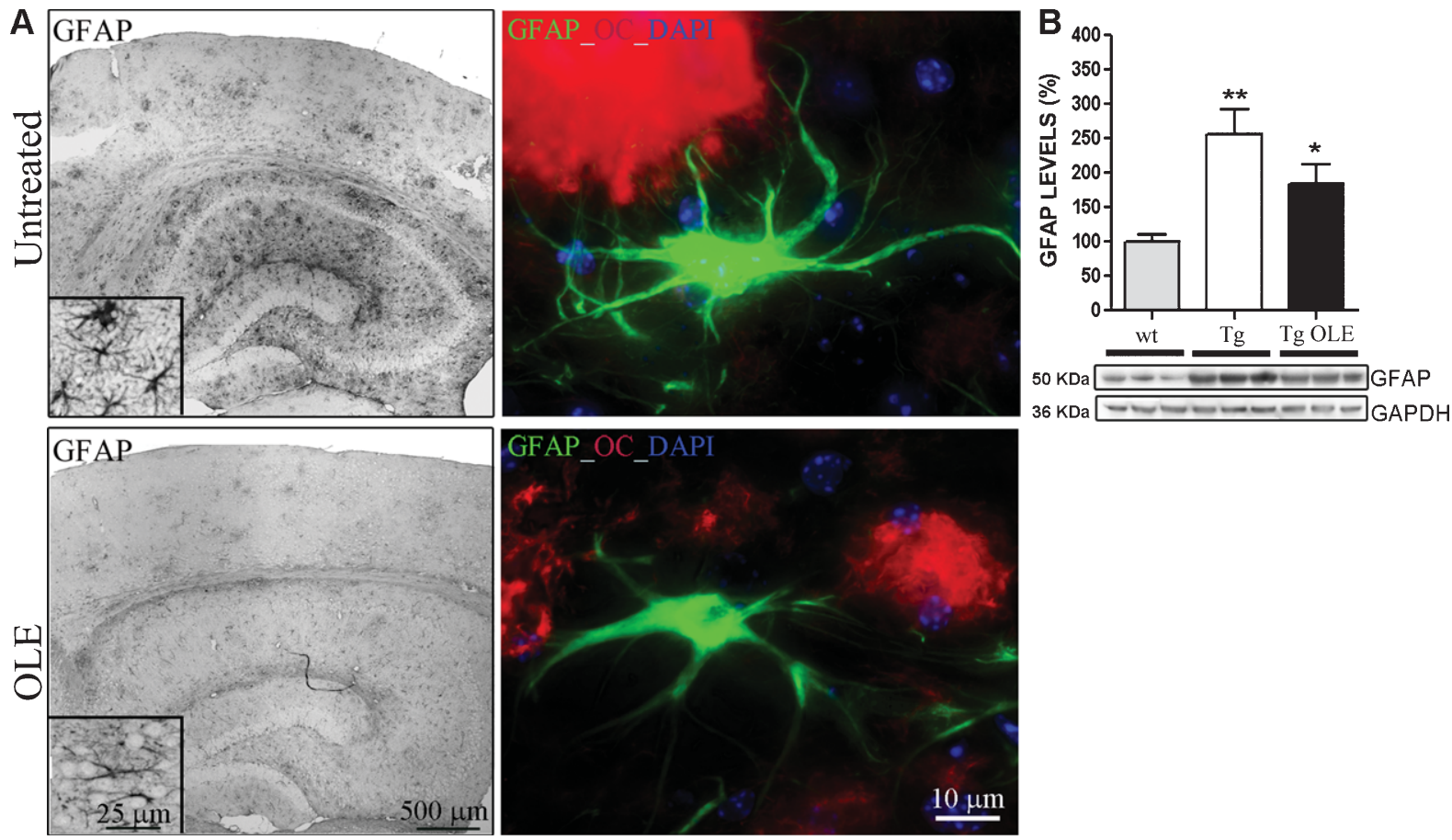

Fig. 3. Glial fibrillary acidic protein (GFAP) immunoreactivity and levels in untreated and OLE-fed TgCRND8 mice. A) Left panels, reconstruction of representative photomicrographs of GFAP immunoreactivity in the cortex and hippocampus of 12-month-old untreated and OLE-treated Tg mice; Right panels: hypertrophic astrocytes (green) with long and thick branches were detected in the brain of untreated Tg mice in the plaque (red, OC antibody) surroundings. In OLE-fed animals astrocyte (green) activation in the fluffy plaque (red, OC antibody) surroundings was considerably milder. B) Western blotting quantitative analysis of GFAP levels in the hippocampus of 12-month-old OLE-fed Tg and untreated wt and Tg mice, $n=5-6$ mice/group $\left({ }^{*} p<0.05\right.$, wt versus Tg OLE; ${ }^{* *} p<0.01$ wt versus Tg; One Way ANOVA plus Newman-Keuls Multiple Comparison Test).

autophagy (namely macroautophagy), a mammalian target of rapamycin (mTOR)-dependent lysosomemediated catabolic pathway responsible for turnover of long-lived proteins and organelles, appears to play a key role. Autophagy protects neurons against environmental stresses such as starvation and $A \beta$-induced cytotoxicity, suggesting its possible role in $A \beta$ clearance. The picture is made even more complex by the data showing that increased mTOR signaling, and hence depressed autophagy, seems to be induced by $\mathrm{A} \beta$ peptides; accordingly, it has been suggested that $A \beta$-mediated mTOR activation could contribute to early cognitive deficits in AD. These and other data support the notion that autophagic dysfunction may represent a key molecular link between brain aging, $\mathrm{A} \beta$ accumulation in the brain parenchyma, and cognitive impairment. By contrast, autophagy stimulation [43] or reversal of autophagy dysfunction by different treatments has been shown to ameliorate amyloid pathologies [42] such that it is increasingly recognized that induction of autophagy might be useful to protect against neurodegeneration and $\mathrm{A} \beta$ peptide toxicity $[44,45]$.
We have recently found a remarkable induction of the autophagic pathway in the cortex of OLEfed young and old $\mathrm{Tg}$ mice. In these animals, OLE administration triggers the autophagic machinery and favors autophagosome substrate delivery to lysosomes for cargo degradation [18]. Specifically, a strong punctuate immunoreactivity and higher levels of autophagosome-lysosome markers such as Beclin-1, the lipidated derivative of LC3 and cathepsin B, were detected in the cortex and, to a lesser extent, in hippocampal areas of OLE-fed Tg mice at all stages of the pathology, as compared to untreated age-matched controls $[5,18]$. Although to a lesser extent than in OLE-fed Tg mice, Beclin-1 and LC3 immunoreactivities were also more intense in OLE-fed wt mice than in untreated animals, supporting a general effect of OLE as an autophagy inducer.

Various signaling pathways are involved in macroautophagy stimulation. As pointed out above, the canonical pathway involves mTOR Complex 1 (mTORC1), a cytosolic complex of five proteins including mTOR, a primordial negative regulator of autophagy. mTOR is inhibited by stress conditions 

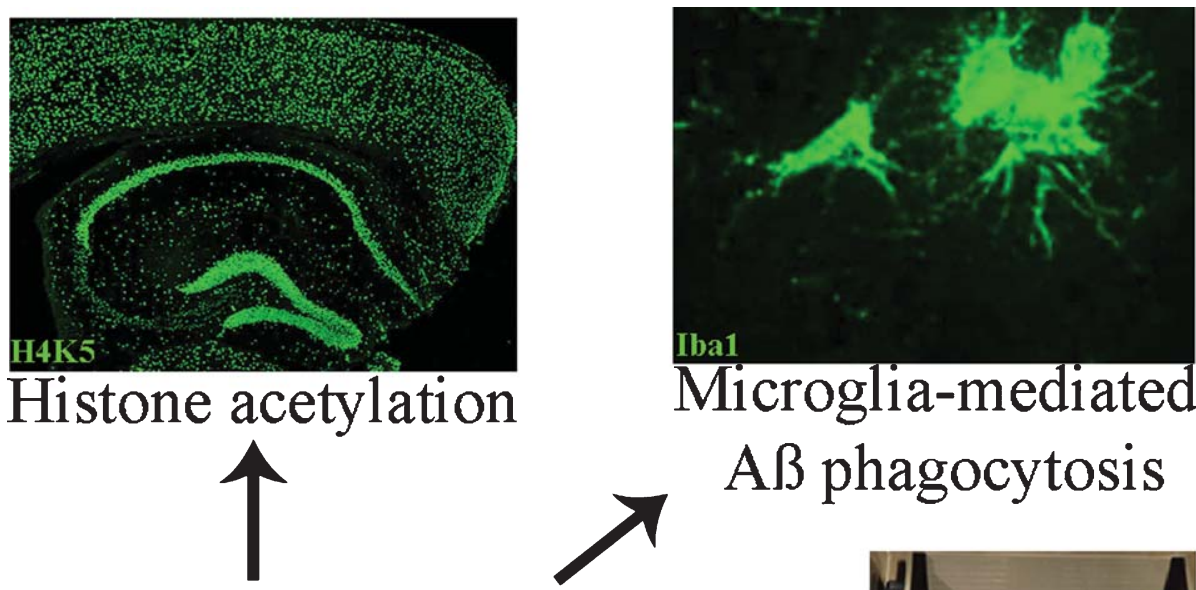<smiles>C/C=C/[C@H](O)O/C=C(/CCC(=O)OCCc1ccc(O)c(O)c1)C(=O)O</smiles>
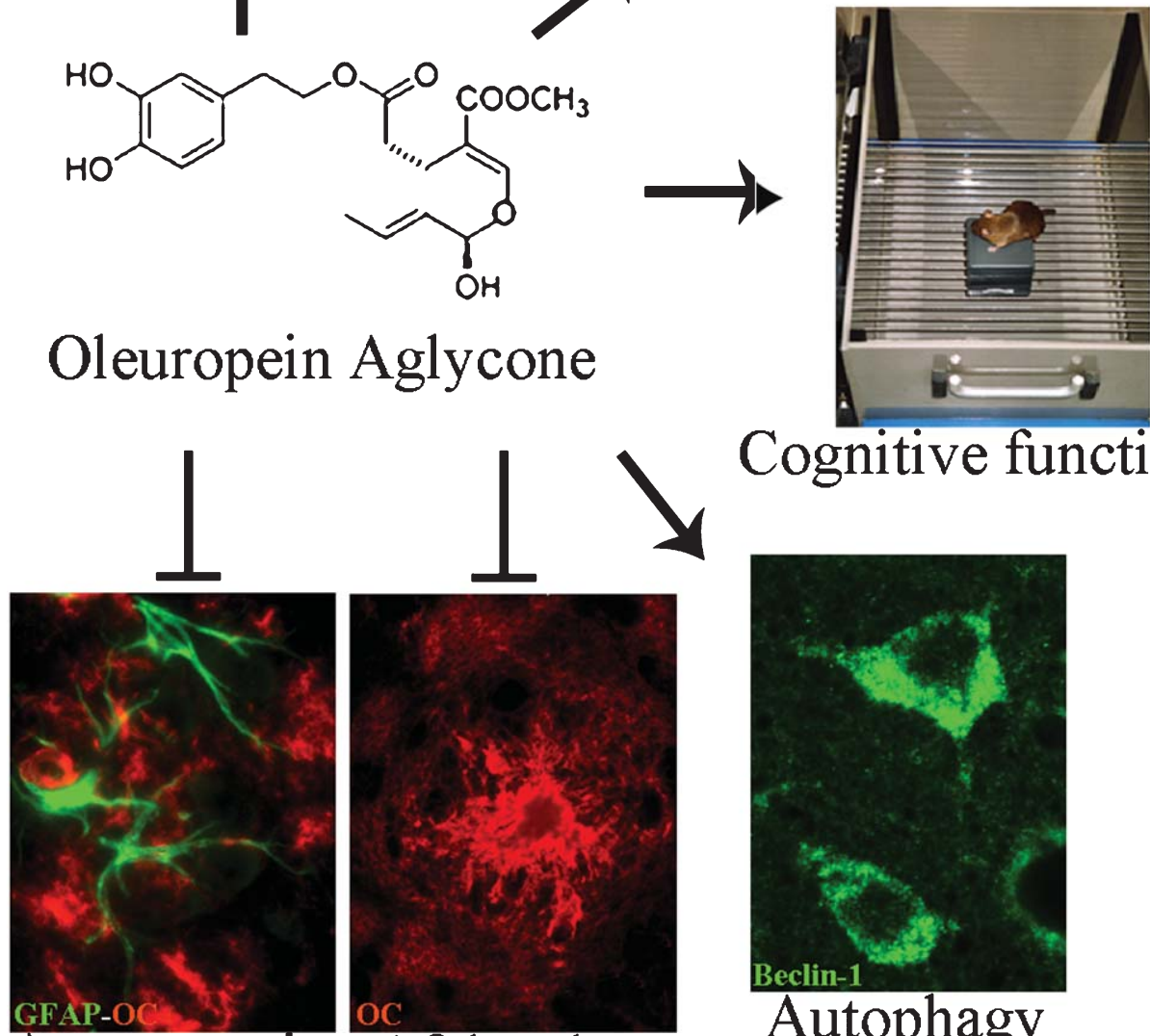

Cognitive functions

\section{Oleuropein Aglycone}

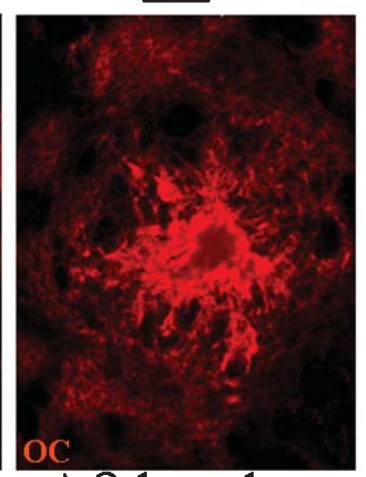

$\mathrm{A} \beta$ burden

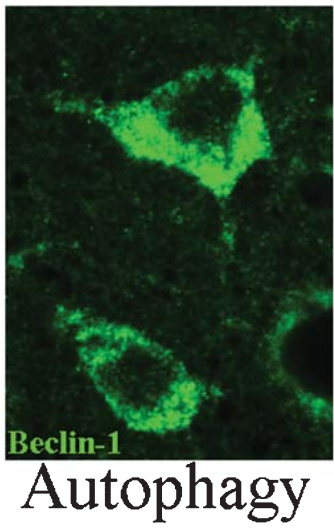

Fig. 4. Schematic representation of effects and cellular targets of OLE in TgCRND8 mice.

such as starvation that result in activation of mTOR targets. mTOR inhibitors such as rapamycin display similar effects, leading to propose it as a new tool to fight neurodegeneration [43]. Autophagy can be triggered also by mTOR inhibition through phosphorylation by AMP-activated protein kinase (AMPK), a stress-induced kinase activated by phosphorylation triggered with a number of signals associated with cellular energy homeostasis such as an increase of the AMP/ATP ratio and the serine/threonine kinase liver kinase B1 (LKB1) [47]. AMPK can also be activated by a rise of the cytosolic $\mathrm{Ca}^{2+}$. The resulting $\mathrm{Ca}^{2+} /$ calmodulin complex activates the calcium/calmodulin-dependent protein kinase kinase 2 (CAMKK2), a kinase expressed in the CNS where it plays key roles in axon and synaptic plasticity; in turn, 
the activated CAMKK activates AMPK by phosphorylation [48]. In our mouse model, autophagy activation by OLE could not directly involve mTOR; in fact, our unpublished data with OLE-exposed cultured SHSY$5 \mathrm{Y}$ cells suggest that in these cells of neuronal type autophagy is triggered following AMPK activation.

\section{OLE MODULATES EPIGENETICS IN Tg MICE}

Accumulating evidence indicates epigenetic deregulation (DNA methylation, histone methylation, acetylation, and phosphorylation) of gene expression in many pathological states, from cancer to cardiovascular diseases and metabolic disorders; in particular, epigenetics appear to play an important role in agerelated memory impairment and in the pathogenesis of neurodegenerative diseases. In particular, proper levels of histone acetylation appear of the outmost importance to delay aging and to hinder neurodegeneration. Histone acetylation is thought to be associated with an "open" chromatin conformation and transcriptional activation, while histone deacetylation is considered to be involved in transcriptional repression resulting from a "closed" chromatin structure [49]. Histone acetylation levels are the result of a balance between the activities of histone acetyltransferases and histone deacetylases (HDACs). Abnormal acetylation of histones is involved in learning and memory and might be causally associated to AD pathogenesis [50]; moreover, histone acetylation seems to ameliorate cognitive deficits in $\mathrm{AD}$ animal models [51]. In particular, HDACs, isoform 2, appear to be upregulated in the AD brain, thus reducing the level of histone acetylation and blocking DNA transcription at specific loci. In AD brains, the HDAC2 levels are increased [50] and the balance of histone 3 acetylation is disrupted by soluble $A \beta[52]$.

The above reported results concerning remarkable modifications of the expression of QC and autophagy markers in our OLE-fed Tg mice, together with the effect of SAHA in restoring long-term potentiation in hippocampal slices mimicking that resulting from OLE exposure, supported some involvement of epigenetic modulations by OLE [18]. Our initial study on the OLE-epigenetics relationship has shown that in our TgCRND8 mice HDAC2 expression is increased concomitantly with the reduction of histone 3 and 4 acetylation throughout the cortex and the hippocampus, both contributing to their cognitive impairments and synaptic dysfunctions. Those modifications were fully reverted by OLE treatment [18], even though the mechanistic basis of this effect has not been elucidated yet. Our data support the idea that epigenetic mechanisms, particularly some modification of the histone acetylation level, underlie the neuroprotective effects of OLE and, therefore, can be considered as a new approach to prevent and, possibly, to treat AD patients. On the other hand, presently AD treatments are limited to symptomatic relief, whereas effective therapy is not available yet. Our findings agree with recent data suggesting that the development of effective HDAC inhibitors could be a new promising therapeutic strategy to fight $\mathrm{AD}[51]$.

\section{CONCLUSIONS}

The beneficial effects of the Mediterranean and Asian diets stem from many factors. An important role is increasingly attributed to the content of polyphenols of several foods, including olive oil, red wine, green tea, and spices. Differently from resveratrol, curcumin, and epigallocatechin-3-gallate, extensively studied for their healthy properties, much less knowledge is available on olive oil polyphenols, including OLE. However, recent finding from our and other groups have addressed this theme providing valuable data on the molecular and cellular basis of the beneficial effects of these polyphenols against type 2 diabetes [53], liver steatosis [29], obesity [27], and age-associated neurodegeneration [9].

For what $A \beta$-induced neurodegeneration is concerned, recently reported findings indicate that OLE administration to $\mathrm{Tg}$ mice improves memory and behavioral performance by interfering with $A \beta$ aggregation and restoring the transgene-associated different dysfunctional aspects in the brain of our mouse model of $\mathrm{AD}$. The identified cellular targets include plaque deposition, size, and compactness, the $\mathrm{pE} 3-\mathrm{A} \beta / \mathrm{A} \beta_{42}$ ratio, the inflammatory and the autophagic/lysosomal responses, epigenetics, and the synaptic function (Fig. 4). In conclusion, our results suggest that OLE supplementation could be considered as a new approach to prevent, to delay, and, possibly, to treat AD.

\section{ACKNOWLEDGMENTS}

Supported by the Regione Toscana: "Programma per la Ricerca Regionale in Materia di Salute 2009", by the ECRF 2010-2011 and the Università degli Studi di Firenze. 
Authors' disclosures available online (http://j-alz. com/manuscript-disclosures/14-2850r1).

\section{REFERENCES}

[1] Scarmeas N, Stern Y, Tang MX, Mayeux R, Luchsinger JA (2006) Mediterranean diet and risk for Alzheimer's disease. Ann Neurol 59, 912-921.

[2] Scarmeas N, Luchsinger JA, Stern Y, Gu Y, He J, DeCarli C, Brown T, Brickman AM (2011) Mediterranean diet and magnetic resonance imaging-assessed cerebrovascular disease. Ann Neurol 69(2), 257-268.

[3] Feart C, Samieri C, Barberger-Gateau P (2010) Mediterranean diet and cognitive function in older adults. Curr Opin Clin Nutr Metab Care 13, 14-18.

[4] Feart C, Samieri C, Alles B, Barberger-Gateau P (2013) Potential benefits of adherence to the Mediterranean diet on cognitive health. Proc Nutr Soc 72, 140-152.

[5] Grossi C, Rigacci S, Ambrosini S, Ed Dami T, Luccarini I, Traini C, Failli P, Berti A, Casamenti F, Stefani M (2013) The polyphenol oleuropein aglycone protects TgCRND8 mice against Ass plaque pathology. PLoS One 8, e71702.

[6] Scarmeas N (2013) Mediterranean food for thought? J Neurol Neurosurg Psychiatry 84, 1297.

[7] Rigacci S, Guidotti V, Bucciantini M, Nichino D, Relini A, Berti A, Stefani M (2011) Abeta(1-42) aggregates into non-toxic amyloid assemblies in the presence of the natural polyphenol oleuropein aglycon. Curr Alzheimer Res 8 841-852.

[8] Stefani M, Rigacci S (2014) Beneficial properties of natural phenols: Highlight on protection against pathological conditions associated with amyloid aggregation. Biofactors $\mathbf{4 0}$, 482-493.

[9] Abuznait AH, Qosa H, Busnena BA, El Sayed KA, Kaddoumi A (2013) Olive-oil-derived oleocanthal enhances beta-amyloid clearance as a potential neuroprotective mechanism against Alzheimer's disease: In vitro and in vivo studies. ACS Chem Neurosci 4, 973-982.

[10] Monti MC, Margarucci L, Riccio R, Casapullo A (2012) Modulation of tau protein fibrillization by oleocanthal. J Nat Prod 75, 1584-1588.

[11] Tangney CC, Kwasny MJ, Li H, Wilson RS, Evans DA, Morris MC (2011) Adherence to a Mediterranean-type dietary pattern and cognitive decline in a community population. Am J Clin Nutr 93, 601-607.

[12] Feart C, Samieri C, Rondeau V, Amieva H, Portet F, Dartigues JF, Scarmeas N, Barberger-Gateau P (2009) Adherence to a Mediterranean diet, cognitive decline, and risk of dementia. JAMA 302, 638-648.

[13] Monroy A, Lithgow GJ, Alavez S (2013) Curcumin and neurodegenerative diseases. Biofactors 39, 122-132.

[14] Lim HJ, Shim SB, Jee SW, Lee SH, Lim CJ, Hong JT, Sheen YY, Hwang DY (2013) Green tea catechin leads to global improvement among Alzheimer's disease-related phenotypes in NSE/hAPP-C105 Tg mice. J Nutr Biochem 24, 1302-1313.

[15] Rigacci S, Guidotti V, Bucciantini M, Parri M, Nediani C, Cerbai E, Stefani M, Berti A (2010) Oleuropein aglycon prevents cytotoxic amyloid aggregation of human amylin. $J$ Nutr Biochem 21, 726-735.

[16] Daccache A, Lion C, Sibille N, Gerard M, Slomianny C, Lippens G, Cotelle P (2011) Oleuropein and derivatives from olives as Tau aggregation inhibitors. Neurochem Int 58, 700707.
[17] Diomede L, Rigacci S, Romeo M, Stefani M, Salmona M. (2013) Oleuropein aglycone protects transgenic C. elegans strains expressing Abeta 42 by reducing plaque load and motor deficit. PLoS One 8, e58893.

[18] Luccarini I, Grossi C, Rigacci S, Coppi E, Pugliese AM, Pantano D, la Marca G, Ed Dami T, Berti A, Stefani M, Casamenti F (2015) Oleuropein aglycone protects against pyroglutamylated-3 amyloid-ss toxicity: Biochemical, epigenetic and functional correlates. Neurobiol Aging 36(2), 648-663.

[19] Impellizzeri D, Esposito E, Mazzon E, Paterniti I, Di Paola R, Bramanti P, Morittu VM, Procopio A, Perri E, Britti D, Cuzzocrea S (2012) The effects of a polyphenol present in olive oil, oleuropein aglycone, in an experimental model of spinal cord injury in mice. Biochem Pharmacol 83, 14131426.

[20] Impellizzeri D, Esposito E, Mazzon E, Paterniti I, Di Paola R, Bramanti P, Morittu VM, Procopio A, Britti D, Cuzzocrea S (2011) The effects of oleuropein aglycone, an olive oil compound, in a mouse model of carrageenan-induced pleurisy. Clin Nutr 30, 533-540.

[21] Impellizzeri D, Esposito E, Mazzon E, Paterniti I, Di Paola R, Morittu VM, Procopio A, Britti D, Cuzzocrea S (2011) Oleuropein aglycone, an olive oil compound, ameliorates development of arthritis caused by injection of collagen type II in mice. J Pharmacol Exp Ther 339, 859-869.

[22] Campolo M, Di Paola R, Impellizzeri D, Crupi R, Morittu VM, Procopio A, Perri E, Britti D, Peli A, Esposito E, Cuzzocrea S (2013) Effects of a polyphenol present in olive oil, oleuropein aglycone, in a murine model of intestinal ischemia/reperfusion injury. J Leukoc Biol 93, 277-287.

[23] Miles EA, Zoubouli P, Calder PC (2005) Differential antiinflammatory effects of phenolic compounds from extra virgin olive oil identified in human whole blood cultures. Nutrition 21, 389-394.

[24] Barbaro B, Toietta G, Maggio R, Arciello M, Tarocchi M, Galli A, Balsano C (2014) Effects of the olive-derived polyphenol oleuropein on human health. Int J Mol Sci 15, 18508-18524.

[25] Sarica S, Toptas S (2014) Effects of dietary oleuropein supplementation on growth performance, serum lipid concentrations and lipid oxidation of Japanese quails. J Anim Physiol Anim Nutr (Berl) 98, 1176-1186.

[26] Pallauf K, Giller K, Huebbe P, Rimbach G (2013) Nutrition and healthy ageing: Calorie restriction or polyphenol-rich "MediterrAsian" diet? Oxid Med Cell Longev 2013, 707421.

[27] Shen Y, Song SJ, Keum N, Park T (2014) Olive leaf extract attenuates obesity in high-fat diet-fed mice by modulating the expression of molecules involved in adipogenesis and thermogenesis. Evid Based Complement Alternat Med 2014, 971890.

[28] De Bock M, Derraik JG, Brennan CM, Biggs JB, Morgan PE, Hodgkinson SC, Hofman PL, Cutfield WS (2013) Olive (Olea europaea L.) leaf polyphenols improve insulin sensitivity in middle-aged overweight men: A randomized, placebo-controlled, crossover trial. PLoS One 8, e57622.

[29] Park S, Choi Y, Um SJ, Yoon SK, Park T (2011) Oleuropein attenuates hepatic steatosis induced by high-fat diet in mice. J Hepatol 54, 984-993.

[30] Haass C (2004) Take five-BACE and the gamma-secretase quartet conduct Alzheimer's amyloid beta-peptide generation. EMBO J 23, 483-488.

[31] Selkoe DJ, Schenk D (2003) Alzheimer's disease: Molecular understanding predicts amyloid-based therapeutics. Annu Rev Pharmacol Toxicol 43, 545-584. 
[32] Hayden EY, Teplow DB (2013) Amyloid beta-protein oligomers and Alzheimer's disease. Alzheimers Res Ther 5, 60.

[33] Dickson DW, Crystal HA, Bevona C, Honer W, Vincent I, Davies P (1995) Correlations of synaptic and pathological markers with cognition of the elderly. Neurobiol Aging 16, 285-298

[34] Cheng B, Gong H, Xiao H, Petersen RB, Zheng L, Huang K (2013) Inhibiting toxic aggregation of amyloidogenic proteins: A therapeutic strategy for protein misfolding diseases. Biochim Biophys Acta 1830, 4860-4871.

[35] Chishti MA, Yang DS, Janus C, Phinney AL, Horne P, Pearson J, Strome R, Zuker N, Loukides J, French J, Turner S, Lozza G, Grilli M, Kunicki S, Morissette C, Paquette J, Gervais F, Bergeron C, Fraser PE, Carlson GA, George-Hyslop PS, Westaway D (2001) Early-onset amyloid deposition and cognitive deficits in transgenic mice expressing a double mutant form of amyloid precursor protein 695. J Biol Chem 276, 21562-21570.

[36] Bellucci A, Rosi MC, Grossi C, Fiorentini A, Luccarini I, Casamenti F (2007) Abnormal processing of tau in the brain of aged TgCRND8 mice. Neurobiol Dis 27, 328-338.

[37] Rosi MC, Luccarini I, Grossi C, Fiorentini A, Spillantini MG, Prisco A, Scali C, Gianfriddo M, Caricasole A, Terstappen GC, Casamenti F (2010) Increased Dickkopf-1 expression in transgenic mouse models of neurodegenerative disease. J Neurochem 112, 1539-1551.

[38] Bayer TA, Wirths O (2014) Focusing the amyloid cascade hypothesis on $\mathrm{N}$-truncated Abeta peptides as drug targets against Alzheimer's disease. Acta Neuropathol 127, 787-801

[39] Hartlage-Rubsamen M, Morawski M, Waniek A, Jager C, Zeitschel U, Koch B, Cynis H, Schilling S, Schliebs R, Demuth HU, Rossner S (2011) Glutaminyl cyclase contributes to the formation of focal and diffuse pyroglutamate (pGlu)-Abeta deposits in hippocampus via distinct cellular mechanisms. Acta Neuropathol 121, 705-719.

[40] Morawski M, Schilling S, Kreuzberger M, Waniek A, Jager C, Koch B, Cynis H, Kehlen A, Arendt T, Hartlage-Rübsamen M, Demuth HU, Roßner S (2014) Glutaminyl cyclase in human cortex: Correlation with (pGlu)-amyloid-beta load and cognitive decline in Alzheimer's disease. J Alzheimers Dis 39, 385-400.

[41] Schilling S, Zeitschel U, Hoffmann T, Heiser U, Francke M, Kehlen A, Holzer M, Hutter-Paier B, Prokesch M, Windisch M, Jagla W, Schlenzig D, Lindner C, Rudolph T, Reuter G, Cynis H, Montag D, Demuth HU, Rossner S (2008)
Glutaminyl cyclase inhibition attenuates pyroglutamate Abeta and Alzheimer's disease-like pathology. Nat Med 14, 11061111.

[42] Ghavami S, Shojaei S, Yeganeh B, Ande SR, Jangamreddy JR, Mehrpour M, Christoffersson J, Chaabane W, Moghadam AR, Kashani HH, Hashemi M, Owji AA, Łos MJ (2014) Autophagy and apoptosis dysfunction in neurodegenerative disorders. Prog Neurobiol 112, 24-49.

[43] Bove J, Martinez-Vicente M, Vila M (2011) Fighting neurodegeneration with rapamycin: Mechanistic insights. Nat Rev Neurosci 12, 437-452.

[44] Yang Y, Chen S, Zhang J, Li C, Sun Y, Zhang L, Zheng X (2014) Stimulation of autophagy prevents amyloidbeta peptide-induced neuritic degeneration in PC12 cells. J Alzheimers Dis 40, 929-939.

[45] Rubinsztein DC, Codogno P, Levine B (2012) Autophagy modulation as a potential therapeutic target for diverse diseases. Nat Rev Drug Discov 11, 709-730.

[46] Rubinsztein DC, Marino G, Kroemer G (2011) Autophagy and aging. Cell 146, 682-695.

[47] Samuel MA, Voinescu PE, Lilley BN, de Cabo R, Foretz M, Viollet B, Pawlyk B, Sandberg MA, Vavvas DG, Sanes JR (2014) LKB1 and AMPK regulate synaptic remodeling in old age. Nat Neurosci 17, 1190-1197.

[48] Racioppi L, Means AR (2012) Calcium/calmodulindependent protein kinase kinase 2: Roles in signaling and pathophysiology. J Biol Chem 287, 31658-31665.

[49] Wang J, Yu JT, Tan MS, Jiang T, Tan L (2013) Epigenetic mechanisms in Alzheimer's disease: Implications for pathogenesis and therapy. Ageing Res Rev 12, 1024-1041.

[50] Graff J, Rei D, Guan JS, Wang WY, Seo J, Hennig KM, Nieland TJ, Fass DM, Kao PF, Kahn M, Su SC, Samiei A, Joseph N, Haggarty SJ, Delalle I, Tsai LH (2012) An epigenetic blockade of cognitive functions in the neurodegenerating brain. Nature 483, 222-226.

[51] Adwan L, Zawia NH (2013) Epigenetics: A novel therapeutic approach for the treatment of Alzheimer's disease. Pharmacol Ther 139, 41-50.

[52] Lithner CU, Lacor PN, Zhao WQ, Mustafiz T, Klein WL, Sweatt JD, Hernandez CM (2013) Disruption of neocortical histone H3 homeostasis by soluble Abeta: Implications for Alzheimer's disease. Neurobiol Aging 34, 2081-2090.

[53] De Bock M, Thorstensen EB, Derraik JG, Henderson HV, Hofman PL, Cutfield WS (2013) Human absorption and metabolism of oleuropein and hydroxytyrosol ingested as olive (Olea europaea L.) leaf extract. Mol Nutr Food Res 57, 2079-2085. 